\title{
The Design and Evaluation of Classroom Supports for Seamless Integration of a Dynamic Modeling Tool
}

\author{
Jonathan Singer, Joseph Krajcik and Ronald Marx \\ University of Michigan, 610 E University, Ann Arbor, MI 48109 \\ Tel: 734-764-2774, Fax: 734-763-1504 \\ Email: singer@umich.edu
}

\begin{abstract}
As students are engaged in sustained inquiry supported by technology various challenges arise. One particular challenge is how to introduce learning technologies within a currently enacted curriculum. To meet this challenge student supports must both be imbedded within the technology itself (intrinsic supports) as well as within the classroom (extrinsic supports). Learner centered design research (Soloway 1996; Stratford, 1996, Jackson, et al., 1996) has described several intrinsic supports which facilitates students in learning technologies. This study extends this line of research on the issues of imbedding learning technologies by concentrating on the classroom supports that enables technology to be introduced seamlessly within a curriculum. The technology utilized in this study is a dynamic modeling tool, Model-It, that allows the learner to plan, build, and test dynamic qualitative models.
\end{abstract}

Keywords: modeling, scaffolding, curriculum, science education, educational reform.

\section{Background}

New approaches to science instruction feature inquiry as essential for student learning (Lunetta, 1998). The presumption is students need opportunities to construct knowledge by solving real problems through asking and refining questions, designing and conducting investigations, gathering, analyzing, and interpreting information and data, drawing conclusions, and reporting findings. One pedagogical approach consistent with these constructivist ideas is project-based science (Blumenfeld, et al., 1991)

Features of project-based science (PBS) have been articulated by Krajcik et al. (1994). The features of PBS include: a) a driving question, which encompasses worthwhile, meaningful content, and is anchored in a real-world question, b) investigations that allow students to be immersed in a scientific culture, c) artifacts that allow students to learn and apply concepts, d) collaboration among students, teachers, and others in the community and e) technology that facilitates the scientific endeavor and collaboration. Recent reform efforts from the American Association for the Advancement of Science and the National Research Council are consistent with these views, recommending science be taught in a way that is authentic and engages students in inquiry and collaboration around real life problems to help students build a rich understanding of science.

A challenge for science teachers is how to support inquiry. Research has shown inquiry places many cognitive demands on learners and therefore requires considerable scaffolding (Bass \& Marx, 1997; Brown \& Campione, 1994; Linn, in 1997); One such strategy for supporting sustained inquiry is the use of imbedded learning technologies. Our current work has built upon this foundation and is now focused upon the systematic design of extended inquiry projects, supported by the imbedded use of learning technologies. We refer to the use of computers, software and peripherals that support student learning as "learning technologies." Learning technologies help students and teachers communicate, explore phenomena, find information, conduct investigations, and develop products and communicate with others. Learning technologies can help students actively examine science phenomena, thereby increasing their motivation to learn. We believe that all of these benefits accrue from using learning technologies. However, we understand that learning technologies supplement and enhance the science classroom, they do not replace the teacher or experiences with phenomena.

One learning technology used extensively in our current middle school curriculum is Model-It. Model-It allows the learner to make qualitative models of cause and effect relationships. Through this technology, the user creates objects with which he or she associates measurable, variable quantities called factors and then defines 
relationships between those factors to show the effects of one factor upon another. Relationships can model immediate effects or effects over time. Model-It provides facilities for testing a model and a "Factor Map" for visualizing it as a whole. Students define objects, factors and the relationship between factors' qualities. The student is facilitated in this modeling process by a variety of scaffolds. These scaffolds include features which a) allow for multiple linked representations b) options which hide additional complexity c) learner guidance through sub-tasks and d) prompting for explanations for constructed relationships.

While the intrinsic supports for Model-It have been articulated (Jackson, Stratford, Krajcik, \& Soloway, 1996; Wisnudel-Spitulnik, Stratford, Krajcik \& Soloway, 1998) the strategies for introducing this technology into a sustained inquiry project have not been scrutinized. During the last 2 years of our research with urban middle school students, the introduction of a new technology was accomplished through a training model. When Model-It was introduced to students, they learned how to use the program by constructing models on content which they had personal experiences (factors which affect my grade in science class). However, this material was not related to the science curriculum. This training model has three major limitations. First the training method does not support the students in understanding the concept of modeling. Secondly, the training model does not provide a meaningful context for utilizing the tool. Finally, the training model is an inefficient use of class time, because the content of the training is not related to the science concepts.

In order to address these limitations, a new approach for the introduction of learning technologies was required. This alternative approach utilizes a performance support model in which a series of classroom events (external supports) were developed to facilitate the students in using the tool in context of the inquiry project they were currently engaged. The classroom events that support the student performance of the modeling technology included: a) engagement in a series of experiences that provided the students a body of content knowledge, b) transitioning tasks ground the unfamiliar event (creating dynamic computer-based models) with a familiar classroom event, c) constraining the initial use of unfamiliar task and, d) guiding manipulation of the learning technology.

\section{Research Question}

The purpose of this research is to explore and evaluate the strengths and limitations of utilizing the extrinsic support strategy as a means for introducing a learning technology (Model-It) in a middle school sustained inquiry project. The extrinsic support strategy was evaluated based upon the student's initial constructed models. To what extent could middle school students utilize the qualitative modeling program - Model-It to construct appropriate air quality models when provided with the external scaffolds?

\section{Methodology Setting}

This study was conducted in four middle schools in a large urban center in the Midwest. Four grade seven teachers each having $2-3$ classes containing approximately 35 students partook in the study $(n=240)$. The teachers have a range of preparation and experience in science content and technology. All four schools are traditional neighborhood schools and have moderate technology access (at least one computer lab with internet connectivity). All schools service similar populations which share three basic traits: a) predominantly African-American and Hispanic, b) traditionally below grade level performance on state mandated achievement test and c) large percentages of students on free and reduced lunch. Student models were constructed collaboratively by small groups of two - four students. Construction of the models occurred during the course of $3-4$ class periods after a series of contextualizing learning events.

\section{Performance Support Model}

In order to facilitate the students in constructing the initial models, the teachers engaged the students in a series of specifically scaffolded learning events. Four events define the support model: 1) contextualizing, 2) transition, 3) constraints, and 4) guidance.

The first of these events introduced the students to the content that was modeled (sources and effects of air pollution). This content derived from two learning events, the enacting of a classroom dramatization (The Awful Eight) and from a school nature walk. Both of these activities focused the students on potential sources and effects of 
air pollution. After completing these initial learning events the teachers guided the students through transitioning tasks that concluded with introducing students to the new learning technology.

The transitioning tasks involved the students developing pictures of 6 - 7 things (objects) that either cause or are affected by air pollution. Next, a series of small group and whole class discussions focused upon their pictures guided the class to reach a consensus on what 7 objects to include, and facilitated the construction of a representative class picture (Fig 1). Using the class picture the teacher continued the transition phase by connecting the picture to the learning technology - Model-It.

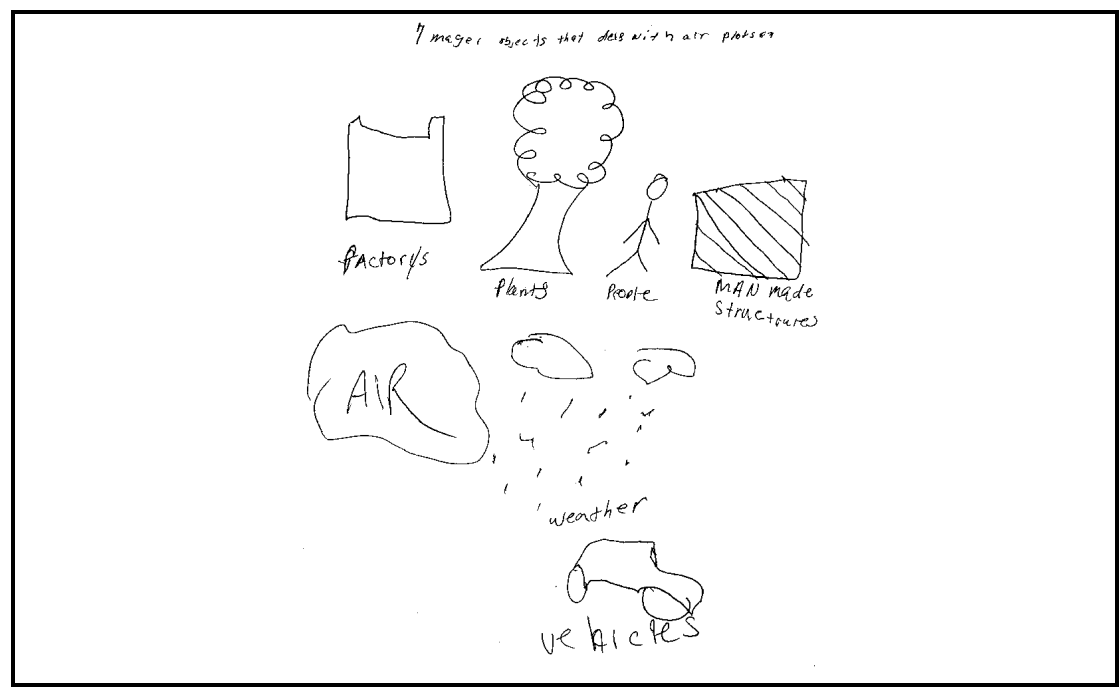

Figure 1. Student representation of Objects

One support feature inherent to Model-It is the opening screen called the "worldview." The worldview feature is a picture, containing the objects utilized in the model (Fig.2). The worldview was developed to have a high degree of similarity with the pictures constructed during the transition phase (Fig. 1). The transition phase concluded with the students making comparisons between their class pictures and the Model-It worldview. Through class discussion, similarities between the two representations were facilitated and the specialized vocabulary terms "object" and "factor" were introduced. An "object" is a physical thing found in the environment. A "factor is a measurable trait associated with an object. For example, "factory" is an object and factors of this object may include "amount of sulfur dioxide released" or " the amount of coal burned".

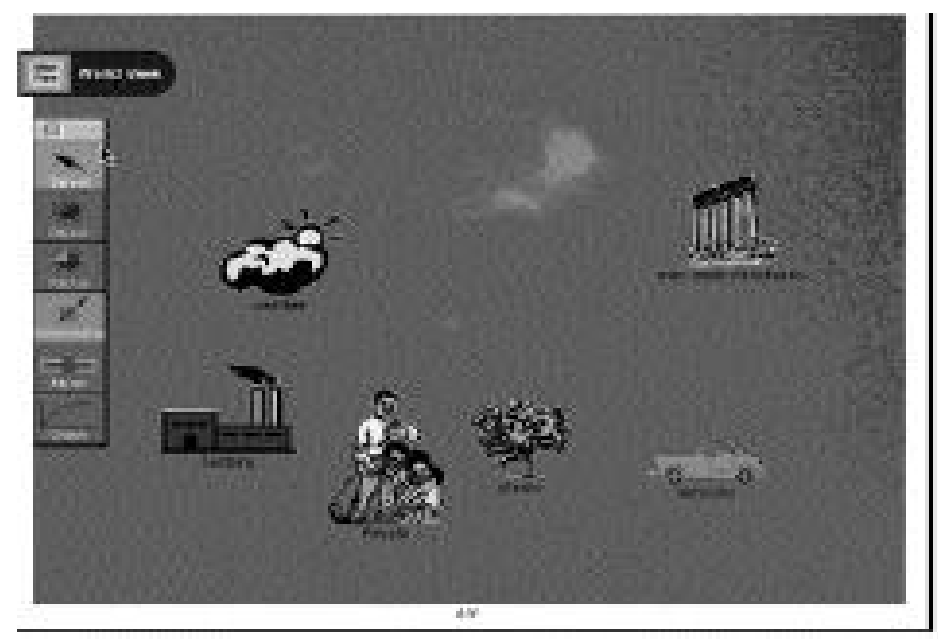

Figure 2. Model-It World view 
Students were supported in their initial computer modeling events by providing tight constraints on the scope of the model. Through teacher guided discussion, the class picture and Model-It worldview were utilized to identify the objects for the initial model. The identified "objects" included "Air", "Factories", "Weather", "People", "Plants", "Vehicles", and "Man made structures." For the first modeling experience, it was strongly recommended the model focus only on the sources of air pollution. This focus requires only three (Air, Factories and Vehicles) of the seven "objects" be used. Selecting an object the teacher demonstrated how to use the information gathered from the two contextualizing learning events to identify measurable traits (factors). For example, the teacher may select vehicle as the object. They would then ask the class to list some traits of a car that can be measured (e.g. mass, amount of exhaust, etc.). After the identification of factors was illustrated, students worked collaboratively to identify factors and record them on worksheets.

Worksheets were designed to mirror the type of information students would need enter into the software. Completing the "Object- Factor" worksheet required students to record the same four critical pieces of information for constructing a factor as the computer program. For each new factor, a student needed to record a) an object, b) an associated factor, c) a description of the factor and d) a textual range for how the factor may vary. The design of the worksheet prompted students to recorded the data in a similar sequence as the prompts in the software (e.g. select object, then factor, then the text range, etc.).

After identifying the objects and factors, the students were ready for guided instruction on how to manipulate the modeling software. The guided instruction followed a general pattern of fading supports. Students were introduced to a manipulation task initially by observing the teacher and then repeating each step. A similar manipulation task would then be conducted through a series of teacher prompts and student manipulations. Finally, the students conduct a third iteration of manipulation on their own followed by a teacher assessment. At the completion of the third manipulation students were able to proceed at their own pace.

\section{Data Source and Analysis}

The main data source for this study were the student computer models. Model analysis utilized quantitative and qualitative methods. Quantitative analysis entailed viewing models and conducting a descriptive analysis that included the number of a) total factors, b) valid factors, c) total relationships and d) valid relationships. Based upon this data, basic descriptive statistics were calculated to describe the student models (Table 1). A sample of the models $(n=15)$ were scored by a trained second rater to determine reliability of the scoring method. The second rater was familiar with both the software and the curriculum materials. The percent of exact agreement between raters ranged from $86 \%-100 \%$ for the four rating scales. Of the sixty individual model components evaluated (4 scales for the 15 models) only one component $(1.7 \%)$ contained a discrepancy of greater than one point.

Table 1: Descriptive statistics of student models $(\mathrm{n}=76)$

\begin{tabular}{|l|l|l|l|l|l|l|}
\hline Statistic & $\begin{array}{l}\text { Total } \\
\text { Factors }\end{array}$ & $\begin{array}{l}\text { Valid } \\
\text { Factors }\end{array}$ & $\begin{array}{l}\text { Percent (\%) } \\
\text { Valid } \\
\text { Factors }\end{array}$ & $\begin{array}{l}\text { Total } \\
\text { Relationship }\end{array}$ & $\begin{array}{l}\text { Valid } \\
\text { Relationship }\end{array}$ & $\begin{array}{l}\text { Percent (\%) } \\
\text { Valid } \\
\text { Relationship }\end{array}$ \\
\hline Sum & 778 & 644 & & 431 & 305 & \\
\hline $\begin{array}{l}\text { Mean per } \\
\text { model }\end{array}$ & 10.0 & 8.3 & 83.8 & 4 & 2.5 & 65.4 \\
\hline Range & $6-19$ & $2-16$ & $41.7-100$ & $1-14$ & $0-13$ & $0-100$ \\
\hline $\begin{array}{l}\text { Standard } \\
\text { Deviation }\end{array}$ & 2.82 & 2.39 & & 3.07 & 3.09 & \\
\hline
\end{tabular}


The qualitative analysis of the student models involved cycles of coding and sorting of the error types that caused a factor or relationship to be classified as not valid. The first cycle of coding involved the evaluation of 76 student models. Common errors that occurred within models and that appeared among multiple schools were identified and used as a means to construct categories of error types. Based upon this method, three major types of errors were identified for "factors" and "relationships." Frequencies of the error occurrences are in Table 2.

Table 2: Frequency of common modeling errors $(n=76)$

\begin{tabular}{|l|l|l|l|l|l|l|}
\hline & \multicolumn{3}{|c|}{ Factors } & \multicolumn{3}{c|}{ Relationships } \\
\hline & $\begin{array}{l}\text { Inappropriate } \\
\text { Object }\end{array}$ & Duplicate & Off Task & Directional & Effect & Off Task \\
\hline $\begin{array}{l}\text { Total } \\
\text { number of } \\
\text { models } \\
\text { with errors }\end{array}$ & 41 & 18 & 10 & 15 & 31 & 31 \\
\hline $\begin{array}{l}\text { Percent (\%) } \\
\text { of models } \\
\text { with error }\end{array}$ & 54 & 24 & 13 & 20 & 41 & 41 \\
\hline
\end{tabular}

Common "factor" errors included: a) inappropriate object association- not a measurable trait of its associated "object", b) duplication - multiple factors represented identical traits, and c) off task - the factor is not related to the purpose of the model. Commonly identified "relationship" errors included: a) directional- relationship illustrated a cause and effect relationship that was reversed, b) direction of effect - relationship illustrated an increasing effect when the appropriate relationship is decreasing and vice verse and c) illogical connection - the factors paired in the relationship are not related. Example errors are illustrated in Figure 3.

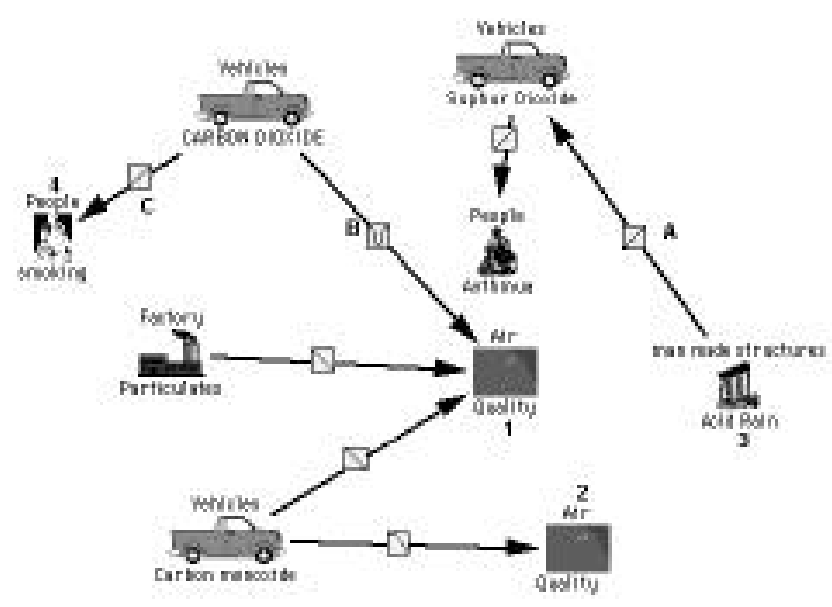

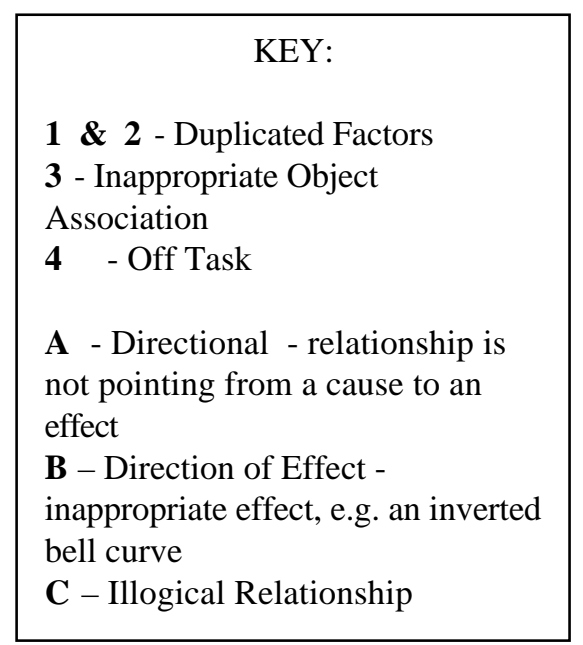

Figure 3. Coded errors of student initial models

A second cycle of model evaluation was performed on a representative sample of the student models. Four or five models from each classroom were randomly selected $(n=41)$ for this analysis. The sample models were analyzed to explore a potential association between "object" selection and proper factor identification. For example, is a student more likely to have greater difficulty identifying factors of "people" as opposed to "vehicle" or "factory." Among this 41-model sample, 83 errors were identified. The identified errors were then coded based on the "object." The frequency of errors is illustrated in Figure 4. 
Frequencies of "Object" specific errors

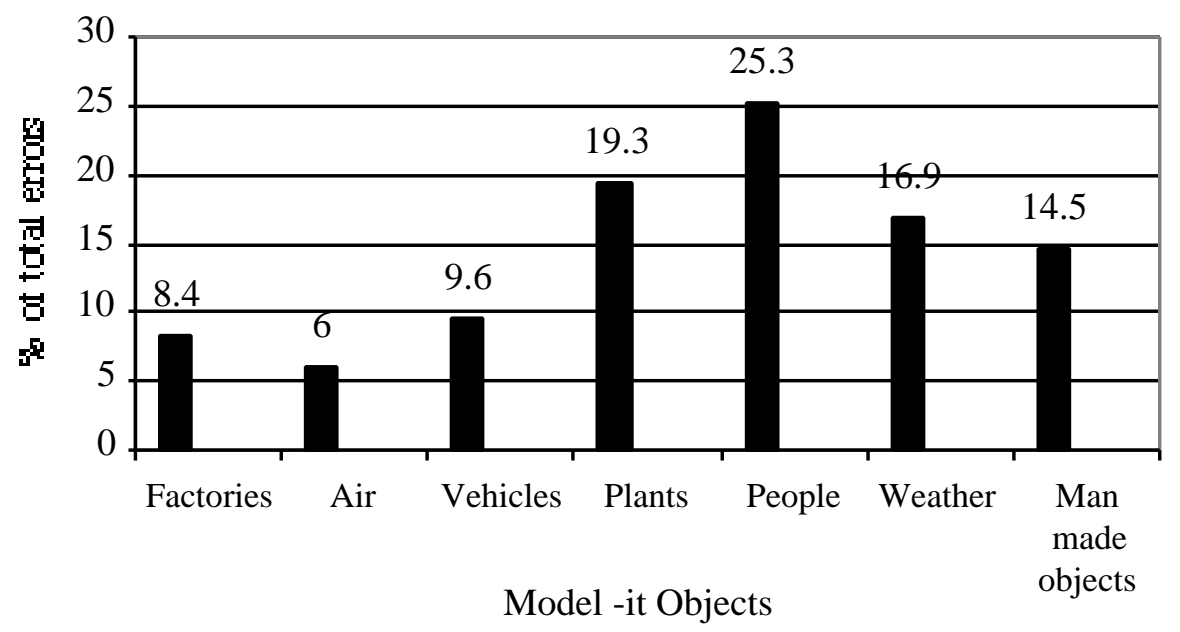

Figure 4. Frequencies of "Object" specific errors

\section{Findings and Interpretations}

Provided with external supports, middle school students utilized the qualitative modeling program - ModelIt to construct appropriate air quality models. Students identified major objects (e.g. Weather, Vehicles, Factories) associated with the contextualizing activities (The Awful 8 play and the school nature walk). In addition to identifying the major objects for the model, students successfully identified relevant factors and relationships for the model. Creating relationships was shown to be a more cognitively demanding task for the students than was constructing factors. While approximately 83 percent of all factors were valid, only 65 percent of relationships were also valid (Table 1). This finding indicates that the support strategy needs to provide greater attention to specific aspects of the model construction process.

The support strategy specifically targeted the introduction of the learning technology. Through the transition phase of the extrinsic support strategy the identification of objects and factors were specifically targeted. The classroom picture was used to identify objects. Teachers provided guidance in using The Awful 8 play and nature walk observations to identify factors. These specific strategies facilitated the initial encounter with the learning technology in which students engaged in the identification of objects and the creation of factors. The facilitation of students in the construction of relationships was treated in a fundamentally different manner. Since students were already introduced and engaged with the technology, the construction of relationships was approached through a mechanical process. The support strategy did not continue with additional cycles of contextualization and transition for understanding relationships (Table 1). Students learned about relationships as an extension of the guided manipulation of the technology. This aspect of the support model is an apparent limitation and needs to be addressed in the next use of Model-It.

Deeper analysis of student factors identified common types of errors and provided insight to the strengths and limitations of the support model. Results from the analysis of student models illustrated that students constructed factors associated with air quality concepts approximately 87 percent (Table 3 ) of the time. While this is a clear strength of the student models sampled, analysis of specific error types indicated a clear difficulty with associating factors with appropriate objects. Over half of the sampled models (54\%) contained errors of this type. Analysis of factor errors according to their associated objects suggests that errors may be deeply curtailed through constraining the scope of the model.

Some objects may provide less intuitive clues for identifying appropriately associated factors. The contextualizing events provide many more explicit examples of factors associated with "vehicles" and "factories" 
than they do for the other five objects. It was for this reason the strategy recommended constraining the students from using other factors. Further analysis of the object specific errors illustrated two very important findings. First, greater than $75 \%$ of the factor errors were associated with four objects (plants, people, weather, and man-made objects) (Fig 4). Secondly, analysis of the object specific errors illustrated that these objects accounted for approximately $97 \%$ of the inappropriate object association error types. To address these error types, additional contextualizing events as a means for introducing objects may be utilized. The currently used events, (The awful eight play, and the school walk) provided sufficient support to introduce 3 objects (Air, vehicles and factories), but not the remaining four. Re-visiting this strategy utilizing events that provided increased clarity of additional objects may alleviate this current limitation.

Students were able to identify basic relationships between their identified factors (e.g. as the number of vehicles increases the amount of $\mathrm{NO}_{2}$ increases and overall air quality will decrease), however, student models also contained numerous relationships that were unrelated to the study of air quality. Over 40 percent of student models sampled contained at least one relationship that was unrelated to the central them of the model, Air Quality (Table 3). As stated earlier, the limited success of students to create meaningful factors indicates that the extrinsic support strategy needs to be modified to provide greater support of this modeling aspect.

\section{Conclusions}

The extrinsic support strategy was moderately successful in facilitating students in the construction of qualitative air quality models. The support strategy was successful in facilitating students in the identification and construction of valid factors, however support for the construction of relationships was limited. Students were successful in utilizing specific components of Model-it (construction of factors) when the task was supported by all four phases of the extrinsic support model. The support strategy did not reach this level of success when all four phases were not brought to together.

The limitations of the support strategy may be explained in terms of how the four phases were applied to the different components of the modeling task. An aspect of the learning technology not considered during the support strategy design was the complexity of the model construction process. Creating a model involves several distinct components (e.g. identifying objects, identifying and constructing factors, and constructing relationships). Any extrinsic strategies designed to facilitate learners in the use of a new technology need to evaluate the technology on the basis of its distinct components as well as the integrated whole. Each fundamental component of a learning technology needs to be supported with all phases of the support strategy. This theory explains why the support model was only marginally successful in scaffolding the construction of ill-defined relationships.

Based upon the emergent theory that all modeling components need to be facilitated by all four phases of the support strategy, the current extrinsic support model will be modified. A natural extension to this study that employs a modified version of this support strategy is currently under investigation. The modification to the support strategy provides greater supports to all phases of model construction. A comparison of the error types and frequency is the focus of this follow-up study.

One major challenge facing many science teachers is how to support sustained inquiry. One such strategy for supporting this endeavor is the use of imbedded learning technologies. Utilizing learning technologies in the classroom, however, requires supports for the learners. We have been investigating the integrated use of one tool, Model-It, as a means to develop a framework of characterizing the traits of scaffolds needed by learners. Although we have had success with integrating one tool, we need to experience and have success with the use of other learning technologies to support inquiry and student learning. The classroom events (external supports) were specifically tailored for the modeling program. Other learning technologies still need to be investigated in order to determine a more robust set of external support principles.

\section{References}

American Association for the Advancement of Science (1993). Benchmarks for Science Literacy. New York: Oxford University Press.

Bass, C., \& Marx, R.W.,(1997). Self regulation in a middle school project-based science classroom. Paper presented at the annual meeting of the American Educational Research Association, Chicago, IL. 
Blumenfeld, P.C., \& Marx, R.W., Patrick, H., \& Krajcik, J. S. (1997). Teaching for understanding. In B.J. Biddle, T.L. Good, and I.F. Goodson (Eds.). International handbook of teachers and teaching. Dordrecht, The Netherlands: Kluwer.

Blumenfeld P., Soloway E., Marx R., Krajcik J., Palincsar, M. \& A. (1994), Motivating project-based learning: sustaining the doing, supporting the learning, Educational Psychologist, 26, 369-398.

Brown, A.L., \& Campione, J.C. (1994). Guided discovery in a community of learners. In K. McGilly (Ed.), Classroom lessons: Integrating cognitive theory and classroom practice (pp. 229-270). Cambridge, MA: MIT Press/Bradford Books.

Cognition and Technology Group at Vanderbilt (1992). The Jasper series as an example of anchored instruction: Theory, program description, and assessment data. Educational Psychologist, 27, 291-315.

Edelson, D. C. (1998). Realising authentic science learning through the adaptation of scientific practice. . In D. Tobin, \& B.J. Fraser (Eds.), International handbook of science education. The Netherlands: Kluwer.

Hoffman, D., \& Novak, T. P. (1998). Bridging the digital divide: The impact of race on computer access and Internet use. Nashville, TN: Owen Graduate School of Management, Vanderbilt University. http://www2000.ogsm.vanderbilt.edu/papers/pdf/digital.divide.PDF.

Jackson,S.,Stratford.S., Krajcik, J. S., \& Soloway, E. (1996). Making system dynamic modeling accessible to pre-college science students, Interactive Learning Environments, 4, 233- 257

Krajcik, J. S., Blumenfeld, P. C., Marx, R. W., \& Soloway, E. (1994). A collaborative model for helping teachers learn project-based instruction. Elementary School Journal, 94, 483-497.

Linn, M.C. (1998). Learning and instruction in science education: Taking advantage of technology. In D. Tobin, \& B.J. Fraser (Eds.), International handbook of science education. The Netherlands: Kluwer.

Lunetta, V.N. (1998). The role of the laboratory in school science. In D. Tobin, \& B.J. Fraser (Eds.), International handbook of science education. The Netherlands: Kluwer.

Marx, R.W., Blumenfeld, P.C., Blunk, M., Crawford, B., Kelly, B., \& Mills, K. (1994). Enacting project-based science: Experiences of four middle school teachers. Elementary School Journal. Elementary School Journal, 94, 517-538.

Marx, R.W., Blumenfeld, P.C., Krajcik, J.S., \& Soloway, E. (1998). New technologies for teacher professional development. Teaching and Teacher Education, 14, 33-52

National Research Council (1996). National Science Education Standards. Washington, DC: National Academy Press.

Roth, W.M., \& Roychoudhury, A. (1993). The development of science process skills in authentic contexts. Journal of Research in Science Teaching, 30, 127-152.

Singer, J., Krajcik, J., \& Marx, R. (1998). Development of extended inquiry projects: A collaborative partnership with practitioners. Paper presented at the annual meeting of the American Educational Research Association, San Diego, CA.

Soloway, E., Krajcik, J., Blumenfeld, P. C., \& Marx, R. W. (1996). Technological support for teachers transitioning to project-based science practices. In T. Koschman (Ed.). CSCL: Theory and practice of an emerging paradigm. Mahwah, NJ: Erlbaum.

Soloway, E., \& Krajcik, J. S. (1996). The Investigator's Workshop: Supporting authentic science inquiry activities, NSF, 1996-1998.

Spitulnik, M. W., Stratford, S., Krajcik, J., \& Soloway, E. (1998). Using technology to support students' artefact construction in science. In. B. J. Fraser \& K. G. Tobin (Eds.), International Handbook of Science Education, (pp. 363-381). Dordrecht, The Netherlands: Kluwer.

Stratford, S., (1996). Investigating processes and products of secondary science students using dynamic modeling software. Unpublished doctoral dissertation, University of Michigan, Ann Arbor.

Wisnudel-Spitulnik, M. (1998). Construction of technological artefacts and teaching strategies to promote flexible scientific understanding. Unpublished doctoral dissertation, University of Michigan, Ann Arbor.

\section{Acknowledgements}

This work was made possible in part by NSF Grant CDA 9616434 and The Center for Learning Technologies Urban Schools. 